\title{
Prior selection prevents the loss of an ecosystem cycle during acidification
}

Sofia J. van Moorsel ${ }^{1,2}$, Justin N. Marleau ${ }^{1}$, Jorge O. Negrín Dastis ${ }^{1}$, Charles Bazerghi ${ }^{1}$, Vincent Fugère ${ }^{1,3}$, Owen L. Petchey ${ }^{2,4}$ and Andrew Gonzalez ${ }^{1}$

${ }^{1}$ Department of Biology, Quebec Centre for Biodiversity Science, McGill University, Montreal, QC, Canada

${ }^{2}$ URPP Global Change and Biodiversity, University of Zurich, Switzerland

${ }^{3}$ Department of Biology, Université de Quebec à Montreal (UQAM), Montreal, QC, Canada ${ }^{4}$ Department of Evolutionary Biology and Environmental Sciences, University of Zurich, Switzerland

E-mail addresses for correspondence:

sofia.vanmoorsel@mail.mcgill.ca

andrew.gonzalez@mgcill.ca 


\begin{abstract}
Ecosystem processes vary temporally due to variation in environmental variables, such as when diurnal variation in sunlight causes diurnal cycles in net primary production. This variability can be characterized by its frequency and amplitude, used to define "normal" functioning of an ecosystem. Relatively little research has addressed how normal modes of variability, such as diurnal cycles, are lost or recovered, following anthropogenic stress. We conducted an aquatic mesocosm experiment to test whether prior application of environmental stress, in the form of moderate acidification, affected the diurnal cycle of dissolved oxygen when exposed to severe acidification. High-frequency data from sensor loggers deployed in 12 mesocosms showed that severe acidification caused a temporary loss of diurnal variation in dissolved oxygen concentration. However, pre-exposure to an acidic environment resulted in the persistence of the diurnal cycle. We hypothesize that preexposure shifted the community to acid tolerant genotypes and/or species of algae and other photosynthetic organisms. Our findings suggest that the stability of ecosystem cycles is intrinsically liked to the stress tolerance of the species assemblage.
\end{abstract}




\section{INTRODUCTION}

Anthropogenic sources of environmental stress such as acidification affect the structure and function of ecosystems by impacting their geochemistry and species composition. Stressors can drive the loss of intolerant species and depending on the degree of compositional turnover, incur a suite of different destabilizing effects such as a loss of diversity (Geelen and Leuven 1986, Niyogi et al. 2003) and/or keystone species (Cuenca Cambronero et al. 2018) and a synchronization of its constituent populations (Thompson et al. 2015). A community that has experienced a stressor may differ in structure, function, and stability (e.g. variability stability, or resistance) to those that have not experienced the stress (Ives and Cardinale 2004, Keitt 2008).

Ecosystem processes are known to vary over a range of time scales. Some scales of variability arise from periodic responses to natural cycles in the environment, while others are scales reflect the aggregate response of the community to stochastic variation in the environment (Blasius et al. 1999, Gilg 2003, Keitt 2008). Because scale-specific responses to the environment occur at different periods and amplitudes, it is necessary to assess ecosystem stability at different time scales (Downing et al. 2008). Cyclical responses to natural environmental changes depend on the time scale in focus, from daily (night/day), seasonal (length of day) and annual (length of growing season) fluctuations. For example, freshwater ecosystems are characterized by strong daily fluctuations in oxygen production (Schindler et al. 2017). During the day, when light is present, algal production of oxygen via photosynthesis can be greater than all organismal consumption of oxygen via respiration, leading to increase in dissolved oxygen concentration. In contrast, at night, in the absence of photosynthesis, organismal respiration decreases dissolved oxygen. The higher the primary productivity, the stronger these diurnal cycles (Schindler et al. 2017).

The growth of stress tolerant species can recover ecosystem processes from a certain degree of stress (Rapport et al. 1985). However, at doses initially lethal for all species only rapid evolution can allow the recovery of an exposed community (unless the system is open to immigration of resistant genotypes). Previous work has shown that exposure to nonlethal stress can pre-adapt populations to a subsequent exposure to otherwise lethal press perturbation allowing resident species and genotypes to adjust their physiology and demographic rates (Bell and Gonzalez 2009, 2011, Low-Décarie et al. 2015, Fugère et al. 2020). Exposure to a stressor may thus reduce the effects of subsequent exposure to the same stressor (Bell and Gonzalez 2009, 2011, Low-Décarie et al. 2015, Fugère et al. 2020) due to selection for tolerant/resistant genotypes within the populations comprising the community. 
The diurnal cycle of DO is a metric for ecosystem functioning (Venkiteswaran et al. 2008, Demars et al. 2015, Schindler et al. 2017) capturing the activity of aquatic species across trophic levels from decomposers to zooplankton (Cowan et al. 1996). We therefore tested the hypothesis that a pre-selective environment could enable communities to maintain their diurnal DO cycle when subsequently exposed to a lethal level of stress, i.e. maintain a 'normal' (as measured in controls) frequency and magnitude of diurnal variability of the DO cycle during the press acidification treatment. We take a "black-box" approach with this whole-ecosystem approach, which comes at the expense of specific mechanisms. We used a high-resolution DO time series from a 5-month long experiment in mesocosms containing 1000 liters of lake water and natural plankton communities. We carried out a multi-phase experiment using acidification as the stressor. In phase 1, we imposed selective environments by manipulating pre-exposure to sublethal stress (with weekly addition of sulfuric acid to the ponds). Then, in phase 2 , all ponds were exposed to a one-time lethal dose of sulfuric acid resulting in $\mathrm{pH} 3$ continuously for several weeks.

\section{METHODS}

\section{Field site and design}

This mesocosm study was conducted within the Large Experimental Array of Ponds (LEAP) platform at the Gault Nature Reserve in Mont-St-Hilaire, QC, Canada ( $45^{\circ} 32^{\prime} \mathrm{N}$, $73^{\circ} 08^{\prime} \mathrm{W}, 122 \mathrm{~m}$ a.s.1.). The experiment was run between May and October 2018 for a total of 147 days. On 24 May 2018, 105 mesocosms (1100L stock tanks, Rubbermaid, Huntersville, $\mathrm{NC}$, USA), henceforth referred to as ponds, were filled with approximately 1000 liters of unfiltered lake water from nearby oligotrophic Lac Hertel, located $1 \mathrm{~km}$ upstream of the experimental facility. Lac Hertel is situated within a UNESCO biosphere reserve and has a fully forested and protected watershed, free of agricultural run-off and other pollution. The lake has no recorded history of acidification. One day after the ponds were filled, all ponds received $50 \mathrm{ml}$ of a nutrient solution containing nitrogen and phosphorus $\left(86.128 \mathrm{~g} / 1 \mathrm{KNO}_{3}\right.$, $1.78 \mathrm{~g} / 1 \mathrm{KH}_{2} \mathrm{PO}_{4}, 2.24 \mathrm{~g} / 1 \mathrm{~K}_{2} \mathrm{HPO}_{4}$, which resulted in the total addition of $596.45 \mathrm{~g}$ of $\mathrm{N}$ and $39.8 \mathrm{~g}$ of $\mathrm{P}$ ) to increase nutrient levels and stimulate primary production.

As a measure of ecosystem functioning, we used dissolved oxygen (DO). DO is both determined by biological factors (e.g. community biomass and composition) and by environmental factors such as water temperature (Belley et al. 2016), as the solubility of oxygen decreases as temperature increases (Wetzel 2001). We tracked DO dynamics in twelve ponds using sensor loggers (MiniDOTs, PME, Vista, California, USA) attached to the 
side of the ponds with rope and positioned into the water column at a depth of approximately $20 \mathrm{~cm}$. We focus our analysis on this subset of 12 mesocosms that generated high frequency time series of DO. Water temperature $\left({ }^{\circ} \mathrm{C}\right)$ and dissolved oxygen (in $\left.\mathrm{mg} / \mathrm{l}\right)$ was measured every 20 minutes. Ponds were covered with $1 \mathrm{~mm}$ netting (vegetable garden netting) to prevent insects, foliage, and debris from entry. Periphyton growth on the side of the ponds or on the loggers was minimal. Four loggers were in mesocosms at $\mathrm{pH} 5.5$, four at $\mathrm{pH} 6.5$ and four at $\mathrm{pH} 8.5$ (see Fig. 1). We present dissolved oxygen corrected for temperature as \% saturation in Fig 1 and all subsequent analyses (described below) focused on temperaturecorrected values ( $\%$ saturation). Outlier values $>4$ standard deviations away from the mean DO across all data points (98\%) were attributed to temporary probe disturbance or malfunction and were thus excluded from analyses of DO across time and mean DO per phase. These values (DO saturation $<40 \%$ or $>150 \%$ ) represented $0.4 \%$ of all data points. Due to the robustness of the wavelet analysis, no data points were excluded from those analyses. We assumed that all ponds had a similar wind exposure and gas exchange coefficient, and thus did not correct oxygen data for gas exchange with the atmosphere.

\section{Acidification treatment}

During the four weeks of phase 0 from 24 May to 26 June ecosystems were at their natural $\mathrm{pH}$ (phase 0 , mean $\mathrm{pH}=9.03 \pm 0.17$ on June $7,8.27 \pm 0.15$ on June 12 and $8.81 \pm 0.26$ on June 26, Fig. S2). We acidified the pond to induce selection on community composition. Acidification is harmful for freshwater systems causing population declines for higher trophic levels (e.g. fish and zooplankton ) and shifts towards a simplification of community composition for lower trophic levels, such as phytoplankton (Locke and Sprules 1994, Schindler et al. 1996, Weiss et al. 2018). On day 34 of the experiment (26 June 2018), we acidified the ponds to start our selection treatment (phase 1). Using sulfuric acid, four ponds were acidified to $\mathrm{pH} 5.5$ and four ponds were acidified to $\mathrm{pH} 6.5$. The remaining four ponds were left as they were at $\mathrm{pH}$ 8.5. Sulfuric acid was gradually added to the ponds using a pipette and stirred. $\mathrm{pH}$ was measured using a multiparameter sonde (YSI, Yellow Springs, $\mathrm{OH}, \mathrm{USA})$. Weekly acidification maintained the $\mathrm{pH}$ around the target $\mathrm{pH}$-value. Initially strong buffering capacity resulted in weekly increases of the $\mathrm{pH}$, but we succeeded in establishing three distinct $\mathrm{pH}$ levels during phase 1 (Figure S2).

On day 83 of the experiment (14 August 2018), we started phase 2 of the experiment. All ponds were acidified using sulfuric acid to $\mathrm{pH} 3$, except pond A4 which was accidentally acidified to $\mathrm{pH} 2.5$ because the $\mathrm{pH}$ sensor malfunctioned (see Figure S2). On August 16, we 
bioRxiv preprint doi: https://doi.org/10.1101/2020.01.27.921437; this version posted January 28, 2020. The copyright holder for this preprint (which was not certified by peer review) is the author/funder, who has granted bioRxiv a license to display the preprint in perpetuity. It is made available under aCC-BY-NC-ND 4.0 International license.

acidified again to ensure that all ponds were $+/-0.1$ from $\mathrm{pH} 3 ; \mathrm{pH}$ remained stable thereafter until the end of the experiment. The $\mathrm{pH}$ in Pond $\mathrm{A} 4$ never recovered and remained at $\mathrm{pH} 2.5$ so we conducted our analyses with and without this pond for comparison (Figure S2).

A
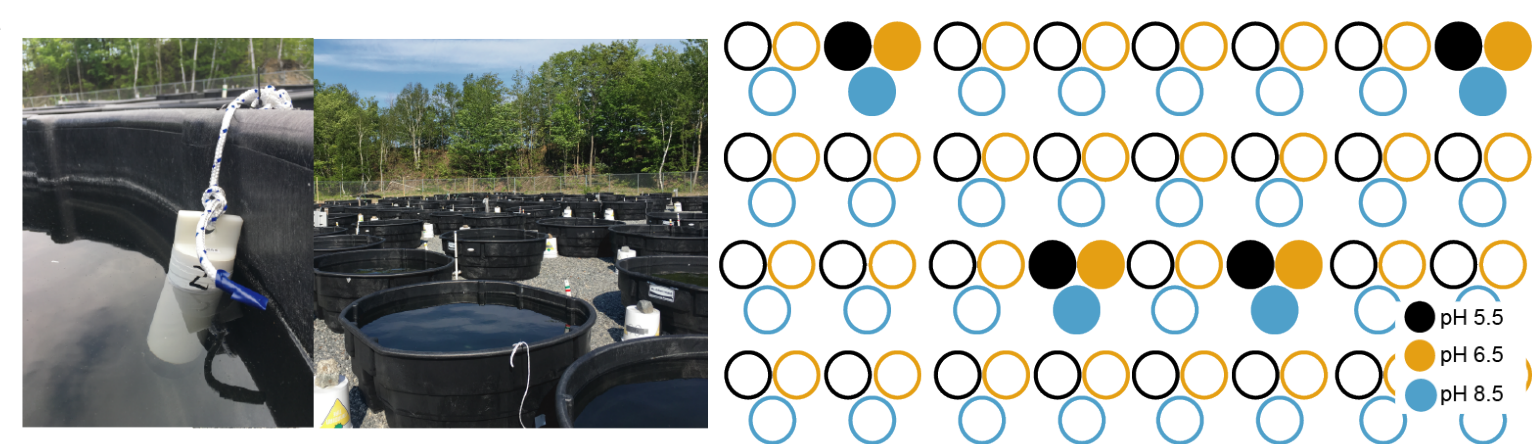

0000

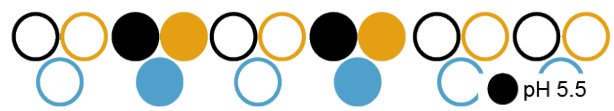

000

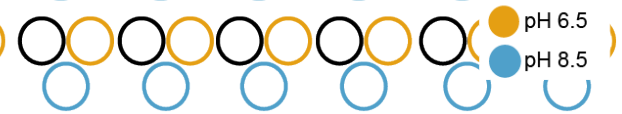

B

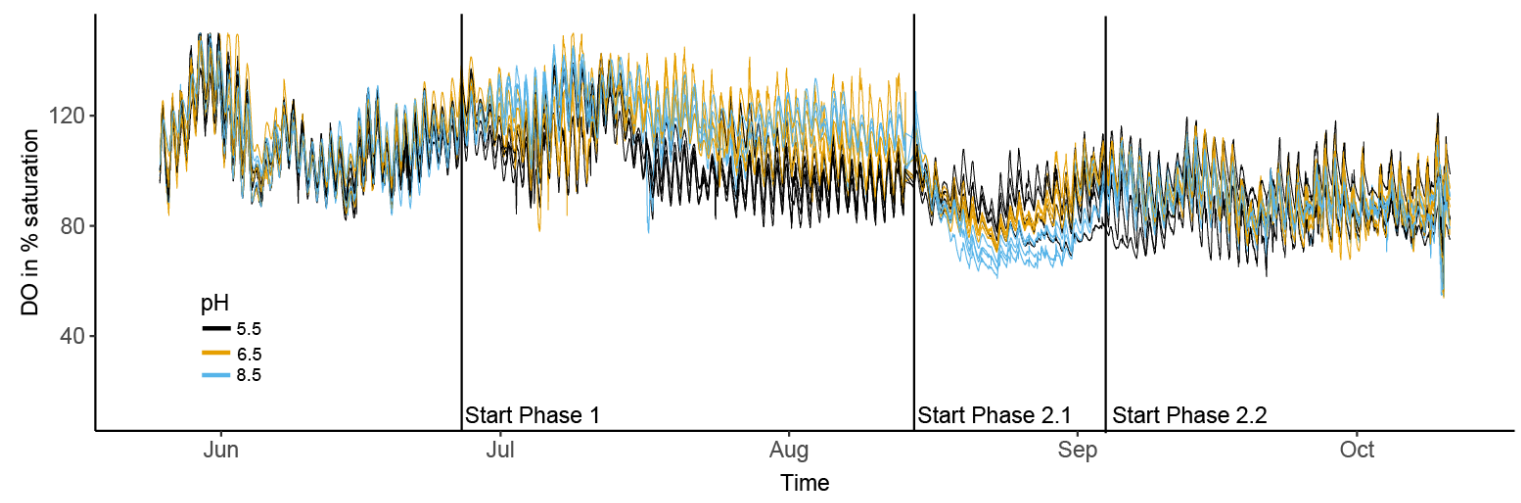

C

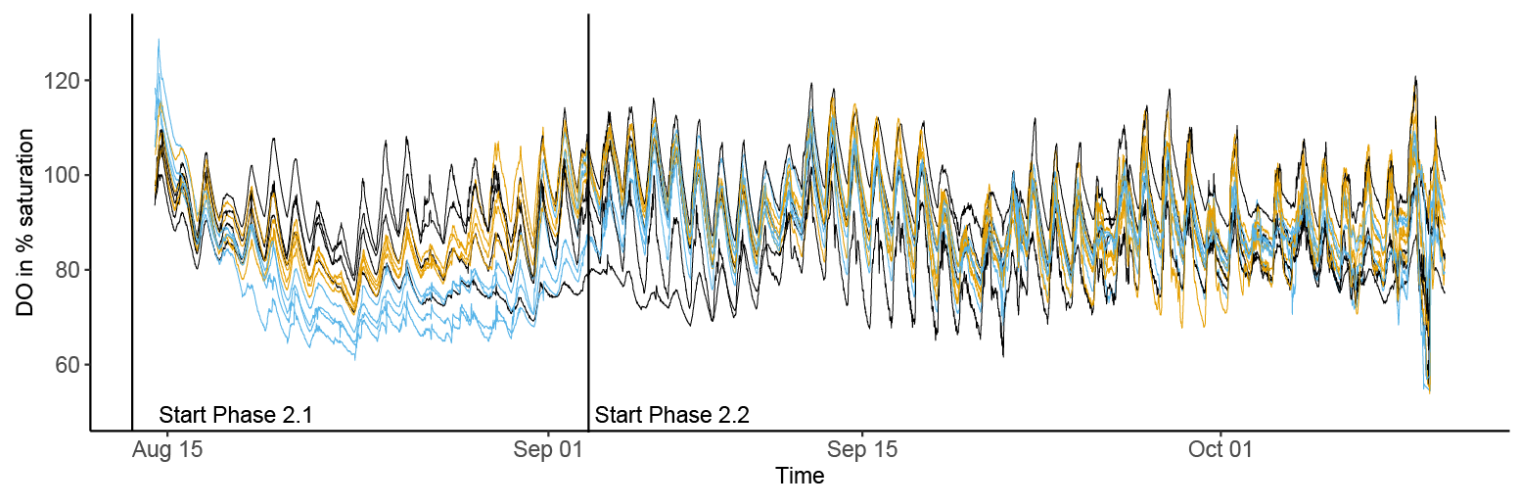

Figure 1. (A) Photographs of the field site and spatial arrangement of the experimental ponds. Filled circles indicate the ponds in which the miniDOT sensor loggers were deployed. (B) Dissolved oxygen in \% saturation over time according to $\mathrm{pH}$ treatment during phase 1. (C) Close up of phase 2 for DO in \% saturation. The start of phase 1 and 2 are indicated with a dashed vertical line. Black lines, $\mathrm{pH} 5.5$, orange lines, $\mathrm{pH} 6.5$ and blue lines, $\mathrm{pH} 8.5$. 


\section{Wavelet analysis}

Under normal conditions the ponds exhibit a daily cycle in DO due to daily cycles in the amount of photosynthesis occurring, hence we were interested in identifying if this daily cycle persisted throughout the acidification treatments across the phases of the experiment. We were also interested in whether the degree of persistence and cycle amplitude depended on the acid pre-exposure treatment. To detect change in the daily period and its amplitude over time we used two continuous wavelet transform algorithms (Grinsted et al. 2004) in Matlab (v2018a) that allowed us to both detect oscillations at multiple frequencies as well as locate their occurrence in time. For our main results, we used the Morlet wavelet (Fig. 2; Grinsted et al. 2004) and the Morse wavelet (Fig. 3; Lilly and Olhede 2012), which lead to similar scalograms, but different normalization schemes, indicating robust results (see Supplementary Information for more details). To identify whether peaks in variability at particular frequencies were statistically significant we used autocorrelated noise as the null variation (Grinsted et al. 2004). With the Morse wavelet transform algorithm, we could extract the amplitude of the daily oscillations for each pond over each phase of the experiment by taking the modulus (or absolute value) of the complex coefficients of the wavelet transform. The period was 1.02 days (closest possible to 24 hours) because of the way the algorithm partitions the periods.

\section{Statistical analysis}

We tested the hypothesis that the daily DO cycle would change with $\mathrm{pH}$ pre-exposure treatment over the phases of the experiment. Our expectation was that the daily DO cycles would be stronger in ponds that had been pre-exposed to lower $\mathrm{pH}$ values $5.5>6.5>8.5$ during phase 1 . The time series was split into four phases and analyzed separately for each phase: phase 0 refers to the time period when no stressor was applied, phase 1 to the time period when the stressor was applied to a subset of the ponds at sub-lethal levels. The initial response of an ecosystem to a pulse perturbation can strongly differ from its long-term response (Arnoldi et al. 2018). Therefore, we separated phase 2 into two sub-phases: phase 2.1 refers to the first approximately three weeks immediately after acidification to $\mathrm{pH} 3$ (August 14 to Sept 3) and phase 2.2, which refers to the rest of the field season from Sept 4 to Oct 15.

Effects of treatments on the extracted amplitudes (modulus) from the wavelet transform at a period of 1.02 days were analyzed using mixed-effects models with $\mathrm{pH}$ during phase 1 as a fixed-effect term ( $\mathrm{pH} 5.5$ vs. $\mathrm{pH} 6.5$ vs. $\mathrm{pH} 8.5)$ and pond $(\mathrm{n}=12)$ as randomeffect term. Mixed models using residual maximum likelihood (REML) were fitted using the 
bioRxiv preprint doi: https://doi.org/10.1101/2020.01.27.921437; this version posted January 28, 2020. The copyright holder for this preprint (which was not certified by peer review) is the author/funder, who has granted bioRxiv a license to display the preprint in perpetuity. It is made available under aCC-BY-NC-ND 4.0 International license.

package nlme for R (Pinheiro et al. 2019). All statistical analyses were conducted using the software R version 3.6.1 (R Development Core Team 2019).

Phase $1 \mathrm{pH}=5.5$

A) Pond A4

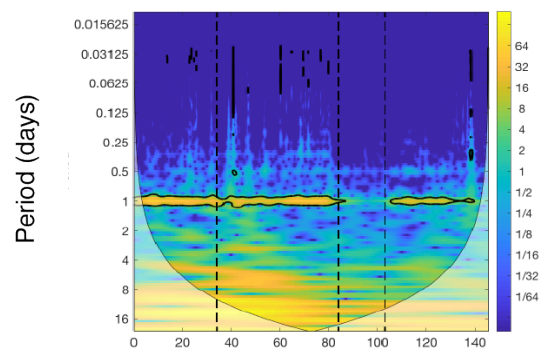

D) Pond D4

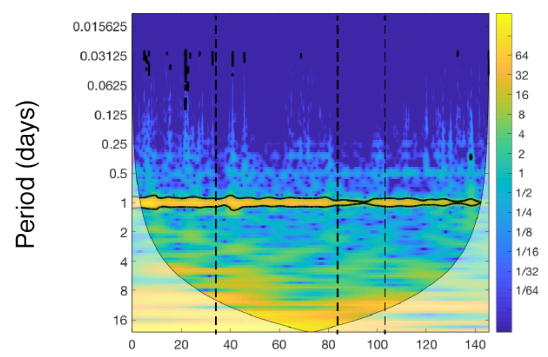

G) Pond J4
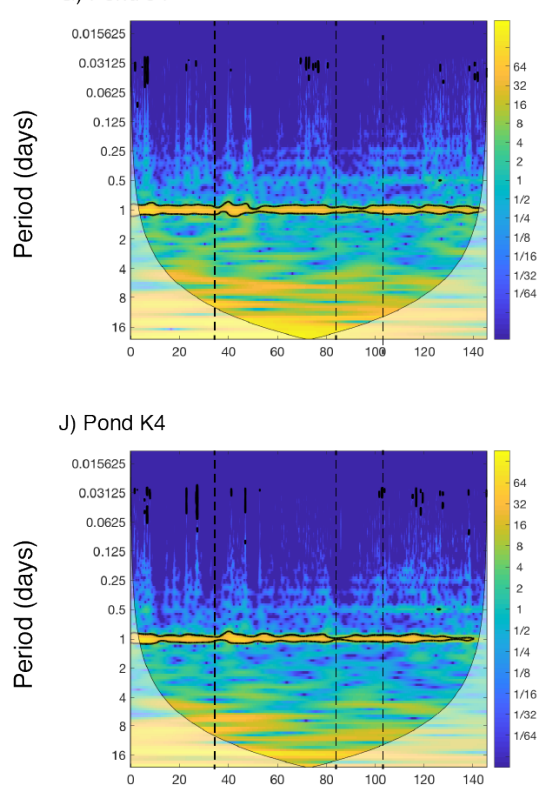

Days since start of experiment
Phase $1 \mathrm{pH}=6.5$

B) Pond A5

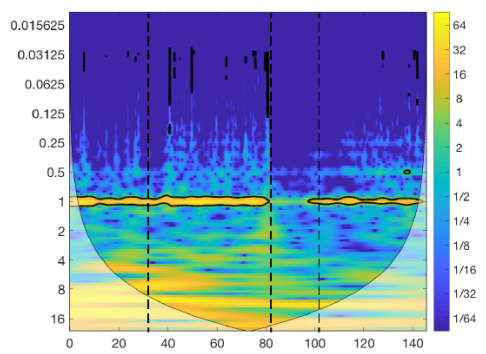

E) Pond D5

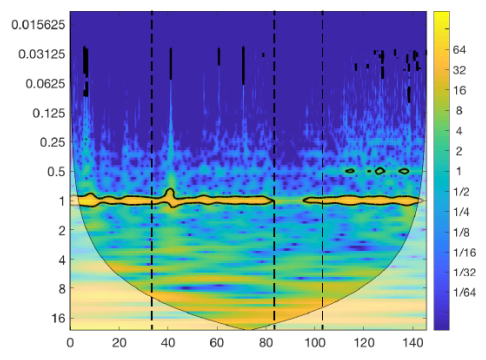

H) Pond J5

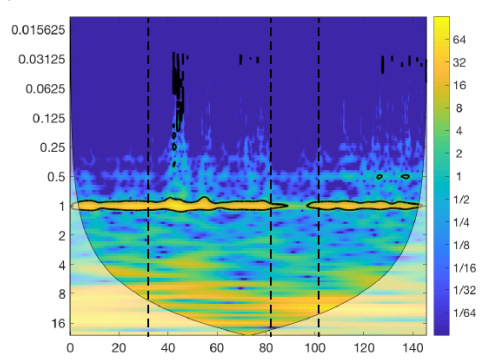

K) Pond K5

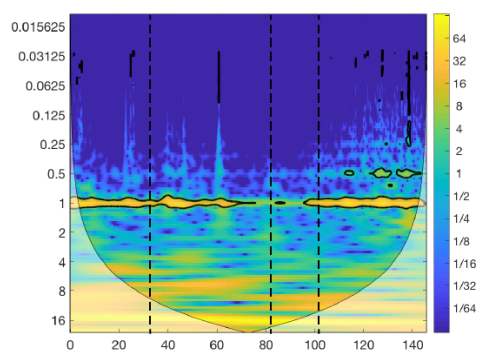

Days since start of experiment
Phase $1 \mathrm{pH}=8.5$

C) Pond A6

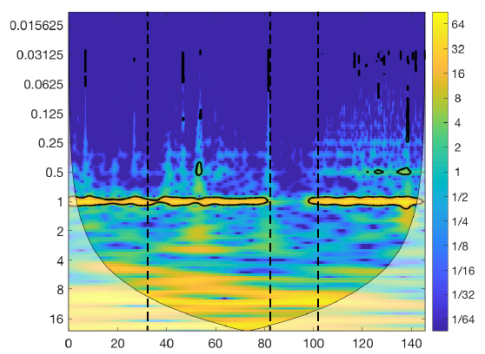

F) Pond D6
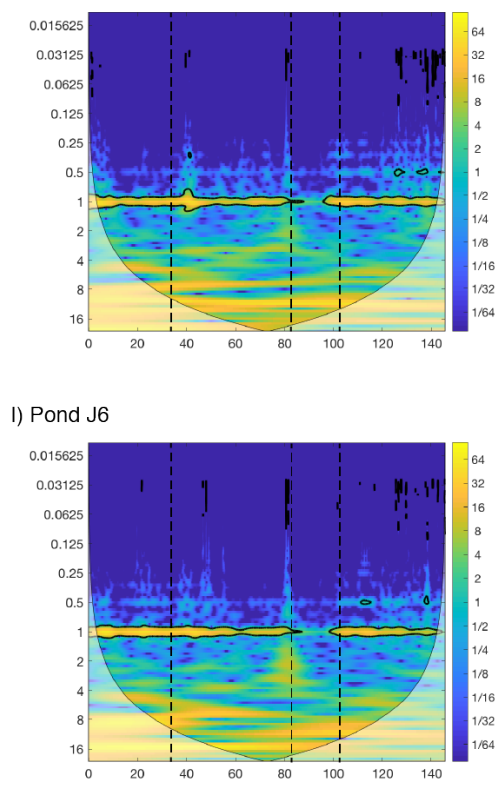

L) Pond K6

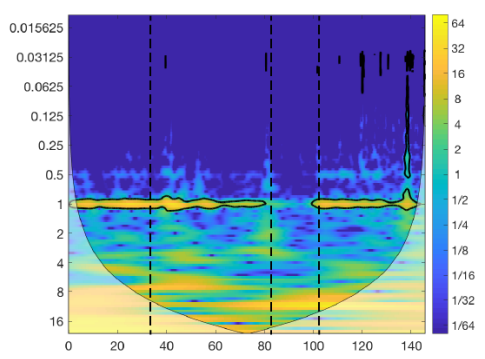

Days since start of experiment

Figure 2. Magnitude scalograms for all ponds with Morlet wavelet. Left row, ponds at $\mathrm{pH}$ 5.5, middle row, ponds at $\mathrm{pH} 6.5$ and right row, ponds at $\mathrm{pH} 8.5$ during phase 1. Dashed lines indicate the start of phase 1 (day 34), the start of phase 2.2 (day 83) and the start of phase 2.2 (day 103). Yellow colors show high energies ("high variation") and blue colors show low energies ("low variation"). Significant variances are circled in black. The time scale increases vertically. The cone depicts the significant area, values outside are based on too little data. See Fig. S5 for visualization of the 1-day period. 


\section{RESULTS}

DO in \% saturation was on average $105 \%$ for the $\mathrm{pH}$ treatment 5.5 during phase 1 , whereas the DO in $\mathrm{pH}$ treatment 6.5 was on average $117 \%$ and thus comparable to the control treatment (pH 8.5) at $118 \%$ saturation (Fig. 1, Table S2, Fig. S4). Upon acidification to $\mathrm{pH} 3$, however, $\mathrm{DO}$ values were significantly higher for the two $\mathrm{pH}$ treatments that experienced a lower $\mathrm{pH}$ during phase 1 for both DO in \% saturation and DO in $\mathrm{mg} / \mathrm{l}$ (phase $2.1, P=0.032$ and $P=0.025$, respectively, Table S2, Fig. S4).

Irrespective of the $\mathrm{pH}$ treatment during the pre-selective phase (phase 1), all ponds demonstrated significant daily cycles in DO (yellow band surrounded by black lines at period of 1 day, Fig. 2). Following acidification to $\mathrm{pH} 3$, those ponds pre-exposed to $\mathrm{pH} 6.5$ (a very mild acidic environment), or not pre-exposed to acid at all, lost their daily DO cycle for approximately two weeks (Fig. 2). In contrast, after exposure to $\mathrm{pH} 3$, three out of the four ponds previously exposed to $\mathrm{pH} 5.5$ during phase 1 maintained their daily DO cycle. The exception was pond "A4", which was accidentally acidified to $\mathrm{pH} 2.5$ and therefore lost its daily cycle, thus showing response more comparable with that of ponds either pre-exposed to pH 6 or not pre-exposed to an acidic environment at all. Ponds pre-exposed to $\mathrm{pH} 5.5$ showed greater variation over the 24 hours after acidification to $\mathrm{pH} 3$ (phase 2.1, Fig. 3B), however the effect was only significant when the outlier pond A4 was excluded (Fig. 3C, Table S1).

At the end of the experiment (phase 2.2 in Fig. 1) we observed the recovery of the daily DO cycle in all twelve ponds.

\section{DISCUSSION}

DO is one of the most important indicators of the functioning of aquatic systems (Rajwa-Kuligiewicz et al. 2015). The amount of dissolved oxygen in the water, and in particular, the diurnal cycle of DO are measures of ecosystem metabolism and ecosystem health (Venkiteswaran et al. 2008, Demars et al. 2015, Schindler et al. 2017). We found that ponds which were pre-adapted to $\mathrm{pH} 5.5$ maintained their natural DO cycle throughout the acidification, whereas ponds held at 6.5 and 8.5 did not. One might even say that the diurnal cycle of dissolved oxygen is the "heart-beat" of aquatic ecosystems. The observed crash of diurnal variability in the mesocosms held at $\mathrm{pH} 6.5$ during phase 1 is thus indicative of the effect of the stress on the maintenance of ecosystem functioning. Acidification can have negative consequences for aquatic life, either via direct physiological impacts on organisms 
bioRxiv preprint doi: https://doi.org/10.1101/2020.01.27.921437; this version posted January 28, 2020. The copyright holder for this preprint (which was not certified by peer review) is the author/funder, who has granted bioRxiv a license to display the preprint in perpetuity. It is made available under aCC-BY-NC-ND 4.0 International license.

(Schindler 1985), selection driven mortality, and via changes in species abundances, and community diversity and composition (Geelen and Leuven 1986, Locke and Sprules 1994).

Despite being exposed to severe stress, we observed a recovery of the DO cycle, at the end of the experiment (phase 2.2 in Fig. 1), although the amplitudes and pattern of fluctuations differed among ponds. Because the DO cycle is mainly driven by phytoplankton (Smith and Piedrahita 1988), we also measured total algal community biomass over time, albeit at a much lower temporal resolution than DO. Acidification generally has a strong effect on algal community composition and can reduce species diversity, but at the same time
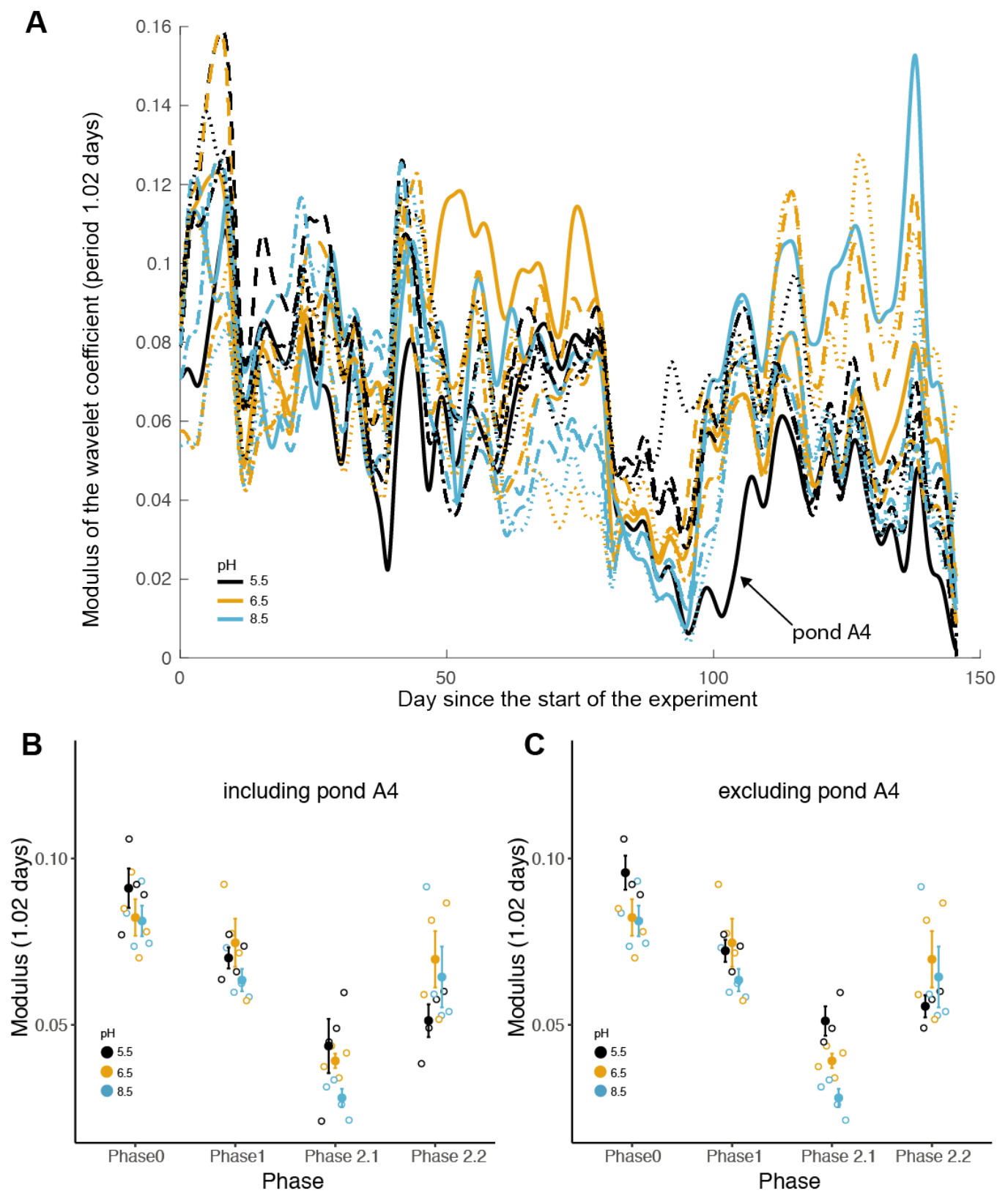

Figure 3. (A) The modulus (absolute value) of the complex coefficients for the Morse wavelet at the 1.02-period scale for each pond over time. The modulus acts like an 'amplitude envelope' capturing the real part of the wavelet coefficient (see Fig. S7) and describes the magnitude of the daily variation across a one-day window. (B) and (C) show means and the associated standard error for the moduli for each phase separately. In (B), the outlier pond A4 is included, in (C) it is excluded. Black lines and points, $\mathrm{pH}$ 5.5; orange lines and points, $\mathrm{pH} 6.5$; blue lines and point, $\mathrm{pH} 8.5$. 
it was shown that community biomass is usually little effect (Geelen and Leuven 1986). We found that the loss of the DO cycle was accompanied by a temporary and strong reduction in algal biomass (Fig. S5) and that the recovery of the DO cycle was paralleled by a recovery of algal biomass during phase 2.1. It is possible that a pure ecological process via sorting could have led to a loss of diversity, but rapid growth of the remaining tolerant algal species quickly compensated the loss of species (Klug et al. 2000). Alternatively, species may have rapidly adapted through phenotypic plasticity (Chevin et al. 2013) or evolution, either via selection on standing genetic variation (Barrett and Schluter 2008) or de novo mutations. Thus, preselection to stress may allow a degree of community tolerance, through a combination of ecological sorting and evolutionary selection which can also maintain ecosystem function (Bell et al. 2019, Fugère et al. 2020). Phytoplankton typically double population sizes within one to a few days, depending on the environmental conditions (Reynolds 1984). It is thus conceivable that selection pressures had an immediate evolutionary impact on the community which resulted in the DO cycle being restored.

We showed very weak effects of pre-exposure to $\mathrm{pH} 6$. In part this might be because the buffering capacity of the ponds resulted in an actual $\mathrm{pH}$ close to 6.5. A pH of 6.5 is circumneutral and commonly experienced in Lac Hertel, the source for our ponds (Kalff 1972). Therefore, a $\mathrm{pH}$ of 6.5 was likely insufficient to induce a community wide tolerance to acidification. In contrast, acidification to $\mathrm{pH} 5.5$ is known to reduce phytoplankton diversity and change phytoplankton community composition (Geelen and Leuven 1986) and likely constituted a stronger selective condition.

Explicit consideration of time scale is critical to modeling associations between variables measured because patterns can change both qualitatively and quantitatively with the scale of analysis (Keitt and Urban 2005, Keitt and Fischer 2006). The loss of diurnal variability represents a loss of function for these aquatic ecosystems, but over longer time scales the maintenance of cycle stability is an indication of community resistance. The wavelet analysis revealed the temporal scales at which acidification had the strongest impact. As per our hypothesis, $\mathrm{pH}$ strongly influenced daily fluctuations in dissolved oxygen. A coarser dataset (e.g. daily or weekly averages of DO) would have obscured our key finding. An important general conclusion is that the analysis of community and ecosystem stability requires the measurement of dynamics at multiple temporal scales, and at frequencies that can detect changes expected at the shortest scales. 


\section{Conclusions}

The rapid and severe ecological impacts associated with the human-caused contamination of aquatic ecosystems make it ever more important to study the conditions allowing communities persist and recover (Bell and Gonzalez 2011, Vander Wal et al. 2012, Geerts et al. 2015). We found that the temporal stability of the DO cycle could be maintained when exposed to extreme stress if the ponds were pre-exposed to intermediate stress (MacGillivray et al. 1995, Flöder and Hillebrand 2012, Wright et al. 2015). Prior exposure to acid stress can attenuated the impact of strong acidification on the DO cycle's persistence and amplitude. Given the strength of the responses we hypothesize that the persistence of the DO cycle involved a joint ecological and evolutionary sorting of the phytoplankton community resulting in an acid tolerant community capable of maintaining a normal ecosystem cycle even at $\mathrm{pH}$ 3. More work is required to uncover the contribution of ecological and evolutionary processes to rapid adaptation and to quantify their ability to restore ecosystem stability in a stressful environment.

\section{Data availability}

All data presented, and all code used will be archived on an online repository upon manuscript acceptance.

\section{References}

Arnoldi, J.-F., A. Bideault, M. Loreau, and B. Haegeman. 2018. How ecosystems recover from pulse perturbations: A theory of short- to long-term responses. Journal of Theoretical Biology 436:79-92.

Barrett, R., and D. Schluter. 2008. Adaptation from standing genetic variation. Trends in Ecology \& Evolution 23:38-44.

Bell, G., V. Fugère, R. Barrett, B. Beisner, M. Cristescu, G. Fussmann, J. Shapiro, and A. Gonzalez. 2019. Trophic structure modulates community rescue following acidification. Proceedings of the Royal Society B: Biological Sciences 286:20190856.

Bell, G., and A. Gonzalez. 2009. Evolutionary rescue can prevent extinction following environmental change. Ecology Letters 12:942-948.

Bell, G., and A. Gonzalez. 2011. Adaptation and evolutionary rescue in metapopulations experiencing environmental deterioration. Science 332:1327-1330. 
Belley, R., P. V. R. Snelgrove, P. Archambault, and S. K. Juniper. 2016. Environmental Drivers of Benthic Flux Variation and Ecosystem Functioning in Salish Sea and Northeast Pacific Sediments. PLOS ONE 11:e0151110.

Blasius, B., A. Huppert, and L. Stone. 1999. Complex dynamics and phase synchronization in spatially extended ecological systems. Nature 399:354-359.

Chevin, L.-M., R. Gallet, R. Gomulkiewicz, R. D. Holt, and S. Fellous. 2013. Phenotypic plasticity in evolutionary rescue experiments. Philosophical Transactions of the Royal Society B: Biological Sciences 368.

Cowan, J., J. Pennock, and W. Boynton. 1996. Seasonal and interannual patterns of sedimentwater nutrient and oxygen fluxes in Mobile Bay, Alabama (USA):regulating factors and ecological significance. Marine Ecology Progress Series 141:229-245.

Cuenca Cambronero, M., H. Marshall, L. De Meester, T. A. Davidson, A. P. Beckerman, and L. Orsini. 2018. Predictability of the impact of multiple stressors on the keystone species Daphnia. Scientific Reports 8.

Demars, B. O. L., J. Thompson, and J. R. Manson. 2015. Stream metabolism and the open diel oxygen method: Principles, practice, and perspectives: Problems in stream metabolism studies. Limnology and Oceanography: Methods 13:356-374.

Downing, A. L., B. L. Brown, E. M. Perrin, T. H. Keitt, and M. A. Leibold. 2008. Environmental Fluctuations Induce Scale-Dependent Compensation and Increase Stability in Plankton Ecosystems. Ecology 89:3204-3214.

Flöder, S., and H. Hillebrand. 2012. Species traits and species diversity affect community stability in a multiple stressor framework. Aquatic Biology 17:197-209.

Fugère, V., M.-P. Hébert, N. B. Costa, C. C. Y. Xu, R. D. H. Barrett, B. E. Beisner, G. Bell, G. F. Fussmann, J. Shapiro, V. Yargeau, and A. Gonzalez. 2020. Community rescue in experimental phytoplankton communities facing severe herbicide pollution. Nature Ecology \& Evolution accepted.

Geelen, J. F. M., and R. S. E. W. Leuven. 1986. Impact of acidification on phytoplankton and zooplankton communities. Experientia 42:486-494.

Geerts, A. N., J. Vanoverbeke, B. Vanschoenwinkel, W. Van Doorslaer, H. Feuchtmayr, D. Atkinson, B. Moss, T. A. Davidson, C. D. Sayer, and L. De Meester. 2015. Rapid evolution of thermal tolerance in the water flea Daphnia. Nature Climate Change 5:665-668.

Gilg, O. 2003. Cyclic Dynamics in a Simple Vertebrate Predator-Prey Community. Science 302:866-868. 
Grinsted, A., J. C. Moore, and S. Jevrejeva. 2004. Application of the cross wavelet transform and wavelet coherence to geophysical time series. Nonlinear Processes in Geophysics $11: 561-566$.

Ives, A. R., and B. J. Cardinale. 2004. Food-web interactions govern the resistance of communities after non-random extinctions. Nature 429:174-177.

Kalff, J. 1972. Net Plankton and Nanoplankton Production and Biomass in a North Temperate Zone Lake. Limnology and Oceanography 17:712-720.

Keitt, T. H. 2008. Coherent ecological dynamics induced by large-scale disturbance. Nature 454:331-334.

Keitt, T. H., and J. Fischer. 2006. Detection of Scale-Specific Community Dynamics Using Wavelets. Ecology 87:2895-2904.

Keitt, T. H., and D. L. Urban. 2005. SCALE-SPECIFIC INFERENCE USING WAVELETS. Ecology 86:2497-2504.

Klug, J. L., J. M. Fischer, A. R. Ives, and B. Dennis. 2000. Compensatory dynamics in planktonic community responses to $\mathrm{pH}$ perturbations. Ecology 81:387-398.

Lilly, J. M., and S. C. Olhede. 2012. Generalized Morse Wavelets as a Superfamily of Analytic Wavelets. IEEE Transactions on Signal Processing 60:6036-6041.

Locke, A., and W. G. Sprules. 1994. Effects of Lake Acidification and Recovery on the Stability of Zooplankton Food Webs. Ecology 75:498-506.

Low-Décarie, E., M. Kolber, P. Homme, A. Lofano, A. Dumbrell, A. Gonzalez, and G. Bell. 2015. Community rescue in experimental metacommunities. Proceedings of the National Academy of Sciences 112:14307-14312.

MacGillivray, C. W., J. P. Grime, and T. I. S. P. (ISP) Team. 1995. Testing Predictions of the Resistance and Resilience of Vegetation Subjected to Extreme Events. Functional Ecology 9:640-649.

Niyogi, Lewis, and McKnight. 2003. Effects of Stress from Mine Drainage on Diversity, Biomass, and Function of Primary Producers in Mountain Streams. Ecosystems 6:540-550.

Pinheiro, J., D. Bates, S. DebRoy, D. Sarkar, and R Core Team. 2019. nlme: Linear and Nonlinear Mixed Effects Models.

Rajwa-Kuligiewicz, A., R. J. Bialik, and P. M. Rowiński. 2015. Dissolved oxygen and water temperature dynamics in lowland rivers over various timescales. Journal of Hydrology and Hydromechanics 63:353-363. 
Rapport, D. J., H. A. Regier, and T. C. Hutchinson. 1985. Ecosystem Behavior Under Stress. The American Naturalist 125:617-640.

Reynolds, C. S. 1984. The Ecology of Phytoplankton. Cambridge University Press.

Schindler. 1985. Long-Term Ecosystem Stress: The Effects of Years of Experimental Acidification on a Small Lake. Science 228:1395-1401.

Schindler, D. E., K. Jankowski, Z. T. A'mar, and G. W. Holtgrieve. 2017. Two-stage metabolism inferred from diel oxygen dynamics in aquatic ecosystems. Ecosphere 8:e01867.

Schindler, D. W., Curtis, Parker, and Stainton. 1996. Consequences of climate warming and lake acidification for UV-B penetration in North American boreal lakes. Nature:705708 .

Smith, D. W., and R. H. Piedrahita. 1988. The relation between phytoplankton and dissolved oxygen in fish ponds. Aquaculture 68:249-265.

Thompson, P. L., B. E. Beisner, and A. Gonzalez. 2015. Warming induces synchrony and destabilizes experimental pond zooplankton metacommunities. Oikos 124:1171-1180.

Vander Wal, E., D. Garant, M. Festa-Bianchet, and F. Pelletier. 2012. Evolutionary rescue in vertebrates: evidence, applications and uncertainty. Philosophical Transactions of the Royal Society B: Biological Sciences 368:20120090-20120090.

Venkiteswaran, J. J., S. L. Schiff, and L. I. Wassenaar. 2008. Aquatic Metabolism and Ecosystem Health Assessment Using Dissolved O2 Stable Isotope Diel Curves. Ecological Applications 18:965-982.

Weiss, L. C., L. Pötter, A. Steiger, S. Kruppert, U. Frost, and R. Tollrian. 2018. Rising pCO 2 in Freshwater Ecosystems Has the Potential to Negatively Affect Predator-Induced Defenses in Daphnia. Current Biology 28:327-332.e3.

Wetzel, R. G. 2001. Limnology: Lake and River Ecosystems. Gulf Professional Publishing. Wright, A. J., A. Ebeling, H. de Kroon, C. Roscher, A. Weigelt, N. Buchmann, T. Buchmann, C. Fischer, N. Hacker, A. Hildebrandt, S. Leimer, L. Mommer, Y. Oelmann, S. Scheu, K. Steinauer, T. Strecker, W. Weisser, W. Wilcke, and N. Eisenhauer. 2015. Flooding disturbances increase resource availability and productivity but reduce stability in diverse plant communities. Nature Communications 6:6092. 
bioRxiv preprint doi: https://doi.org/10.1101/2020.01.27.921437; this version posted January 28,2020 . The copyright holder for this preprint (which was not certified by peer review) is the author/funder, who has granted bioRxiv a license to display the preprint in perpetuity. It is made available under aCC-BY-NC-ND 4.0 International license.

\section{Acknowledgements}

The Canadian Foundation for Innovation and the Liber Ero Chair in Biodiversity Conservation provided funding to A.G. to construct the LEAP pond facility. S.J.V.M. was funded by the Swiss National Science Foundation (grant number P2ZHP3_L81462). O.L.P and S.J.V.M. would like to thank the URPP GCB of the University of Zurich for financial support. We are very grateful to Jihane Benbahtane, Rachel Rolland, Aseel Shakra, Kaushar Kagzi for data collection and David Maneli for technical support in the field.

\section{Author contributions}

A.G., O.L.P, \& S.J.V.M designed the study, S.J.V.M., C.B. \& J.O.N.D. carried out the experiment, S.J.V.M, J.M. \& V.F. analyzed data, S.J.V.M. wrote the paper with substantial contributions of all authors 